\title{
Percepção da equipe de enfermagem sobre o brinquedo terapêutico na hospitalização pediátrica
}

\author{
Perception of nursing team about the therapeutic toy in pediatric hospitalization \\ Percepción de la equipo del enfermería sobre el juguete terapêutico en la hospitalización pediátrica
}

Recebido: 19/04/2021 | Revisado: 26/04/2021 |Aceito: 01/05/2021 | Publicado: 15/05/2021

Jéssyca Karen Campus Januário

ORCID: https://orcid.org/0000-0003-3569-7023

Universidade Federal de Alagoas, Brasil

E-mail: jessyca_karen@hotmail.com

Marcela Barbosa de Farias

ORCID: https://orcid.org/0000-0003-2054-557X

Universidade Federal de Alagoas, Brasil

E-mail: marcelinhaa17@hotmail.com

Ivanise Gomes de Souza Bittencourt

ORCID: https://orcid.org/0000-0002-9416-3964

Universidade Federal de Alagoas, Brasil

E-mail: ivanise.gomes@eenf.ufal.br

Ana Carolina Santana Vieira

ORCID: https://orcid.org/0000-0002-7273-1414 Universidade Federal de Alagoas, Brasil E-mail: ana.vieira@eenf.ufal.br

Mabelly Cavalcante Rego

ORCID: https://orcid.org/0000-0003-3551-8849 Hospital Universitário Professor Alberto Antunes, Brasil

E-mail: mabelly_cavalcante@hotmail.com

Fernanda Ferreira Voss

ORCID: https://orcid.org/0000-0003-1883-5818

Hospital Universitário Professor Alberto Antunes, Brasil

E-mail: fvlv2@hotmail.com

Hallana Laisa de Lima Dantas

ORCID: https://orcid.org/0000-0001-6721-0860 Universidade Federal de Alagoas, Brasil

E-mail: lanavidas@hotmail.com

Ingrid Martins Leite Lúcio

ORCID: https://orcid.org/0000-0003-2738-7527

Universidade Federal de Alagoas, Brasil

E-mail: ingridmll@eenf.ufal.br

\begin{abstract}
Resumo
Conhecer a percepção da equipe de enfermagem sobre o Brinquedo Terapêutico (BT) no cuidado de Enfermagem na hospitalização pediátrica. Estudo descritivo, qualitativo, realizado na Clínica Pediátrica de um Hospital Universitário, do Nordeste Brasileiro. Foram entrevistados 19 profissionais da equipe de enfermagem, no período de setembro a dezembro de 2019 e as falas vistas segundo à análise de conteúdo. Os profissionais de enfermagem mostraram-se sensíveis aos aspectos negativos da hospitalização pediátrica e reconhecem a importância de meios para diminuição desse sofrimento, e apontam como significativo o uso do brinquedo. No entanto, quando indagados quanto ao recurso do BT no processo de cuidado, a percepção difere da sua finalidade e tipos. Os profissionais ainda desconhecem as legislações a respeito do BT, mas ao compartilhar em suas falas experiências de cuidado verifica-se que algumas práticas se aproximam das finalidades do BT. O uso do brinquedo terapêutico no hospital ainda é visto como dissociado do cuidado de enfermagem, mostrando a necessidade de estudos sobre o tema e capacitações e sensibilizações para os profissionais, promovendo a reflexão crítica acerca da prática da equipe de enfermagem frente a esta tecnologia em saúde.
\end{abstract}

Palavras-chave: Jogos e brinquedos; Equipe de enfermagem; Enfermagem pediátrica.

\begin{abstract}
To know the perception of the nursing team about the Therapeutic Toy (BT) in nursing care in pediatric hospitalization. Descriptive, qualitative study, carried out at the Pediatric Clinic of a University Hospital, in northeastern Brazil. 19 professionals from the nursing team were interviewed, from September to December 2019 and the statements seen according to the content analysis. Nursing professionals were sensitive to the negative aspects of pediatric hospitalization and recognize the importance of means to reduce this suffering, and point out that the use of
\end{abstract}


toys is significant. However, when asked about the resource of BT in the care process, the perception differs from that of its purpose and types. Professionals are still unaware of the legislation regarding BT, but when sharing in their speeches experiences of care, it appears that some practices are close to the purposes of BT. The use of therapeutic toys in the hospital is still seen as dissociated from nursing care, showing the need for studies on the theme and training and sensitization for professionals, promoting critical reflection on the practice of the nursing team in face of this technology in health.

Keywords: Play and playthings; Nursing team; Pediatric nursing.

\section{Resumen}

Conocer la percepción del equipo de enfermería sobre el Juguete Terapéutico (BT) en el cuidado de enfermería en la hospitalización pediátrica. Estudio descriptivo, cualitativo, realizado en la Clínica Pediátrica de un Hospital Universitario, en el noreste de Brasil. Se entrevistó a 19 profesionales del equipo de enfermería, de septiembre a diciembre de 2019 y se vieron las declaraciones según el análisis de contenido. Los profesionales de enfermería fueron sensibles a los aspectos negativos de la hospitalización pediátrica y reconocen la importancia de los medios para reducir este sufrimiento, y señalan que el uso de juguetes es significativo. Sin embargo, cuando se le pregunta sobre el recurso de la BT en el proceso asistencial, la percepción difiere de su finalidad y tipos. Los profesionales aún desconocen la legislación sobre BT, pero al compartir en sus discursos experiencias de cuidado, parece que algunas prácticas se acercan a los propósitos de BT. El uso de juguetes terapéuticos en el hospital aún se ve disociado del cuidado de enfermería, evidenciando la necesidad de estudios sobre la temática y formación y sensibilización de los profesionales, promoviendo la reflexión crítica sobre la práctica del equipo de enfermería frente a esta tecnología en salud.

Palabras clave: Juego e Implementos de juego; Grupo de enfermería; Enfermería pediátrica.

\section{Introdução}

A hospitalização representa para a criança uma situação delicada a ser vivenciada. Durante este processo ela passa a conviver com diversos fatores que provocam estresse e angústia para si e seus acompanhantes, como um ambiente desconhecido, longe do convívio familiar, dos amigos, das brincadeiras e da escola. Essas situações podem gerar sofrimento na criança e influenciar nas esferas afetiva, psicológica e emocional que integram o processo de desenvolvimento na infância (Depianti, Melo, \& Ribeiro, 2018).

Assim, o desenvolvimento infantil saudável pode ser prejudicado e interferir diretamente na sua qualidade de vida, com consequências que podem permanecer mesmo após a alta (Rockembach, Espinosa, Cecagno, Thumé \& Soares, 2017). Destaca-se desse modo, a importância de cuidados que vão além dos modelos focados apenas na doença, como aqueles que pautam uma abordagem centrada na criança e na família, observando todos os aspectos desse binômio no seu contexto de vida (Ferreira, Oliveira, Gonçalves, Elias, Medeiros \& Mororó, 2019).

Os profissionais de enfermagem têm um papel fundamental para que esse cuidado em saúde esteja voltado à integralidade da atenção à criança hospitalizada, diminuindo assim, a angústia da criança e da sua família. Devem lançar mão na sistematização do cuidado no uso de técnicas que amenizem o impacto emocional ocasionado pelo processo de adoecimento e assim, auxiliar na aceitação do momento que compreende a hospitalização, bem como, ajudar no processo de recuperação e promover o vínculo entre profissional, criança e família (Ferreira et al., 2019).

Dentre esses recursos destacam-se o brincar livre e a brincadeira, que tornam a hospitalização menos traumática, possibilitando que a criança entre no seu universo infantil, e consequentemente estreitam o vínculo entre profissional, criança e família, proporcionado a dissociação da imagem do enfermeiro apenas a procedimentos dolorosos, bastante frequentes nesse processo (Depianti, Melo,Ribeiro, 2018). A Lei 13.257/2016 que dispõe sobre as políticas públicas para a primeira infância evidencia como o brincar e o lazer constituem uma das áreas prioritárias para as políticas públicas para a primeira infância e assegura-os enquanto direito da criança. Com isso, discrimina-se uma orientação quanto a importância de se resguardar este direito em direntes contextos no qual a criança está inserida, inclusive em ambiente hospitalar (Brasil, 2016).

Em seu estudo, Maia, Soares Ohara e Ribeiro (2019) trazem que o brincar é uma atividade fundamental para a criança e pode ser expresso de diferentes formas, sendo o brinquedo um dos possíveis recursos. Neste universo, apresenta-se uma 
técnica que perpassa o campo do brincar para a criança, mas que se apresenta de modo sistematizado denominado Brinquedo Terapêutico (BT), abordado na literatura como um recurso útil para diminuição da ansiedade decorrente de situações ameaçadoras e atípicas, e que deve ser implementado sempre que a criança tenha necessidade de entender e lidar com experiências, como por exemplo, durante a hospitalização (Almeida, 2019).

O BT pode ser entendido como uma brincadeira estruturada que pode ser utilizada pelos diversos profissionais de saúde, para a criança que requer mais do que o brinquedo recreacional para diminuir os aspectos negativos associados a alguma experiência (Barroso, Machado, Cursino, Silva, Depiant, Silva, 2019). Além disso, Maia et al. (2019) relata que constitui também um significativo meio de comunicação entre o enfermeiro, criança e família, e é um instrumento facilitador para formação do vínculo e consequente bem-estar emocional de todos os envolvidos.

Os relatos de Maia et al. (2019) destacam a utilização do BT por enfermeiros desde década de 1990, assim como apontam sua classificação em três categorias: (1) BT Dramático ou Catártico que propicia à criança a dramatização de experiências novas, a promoção da descarga emocional e a manifestação dos sentimentos, desejos e experiências vividas, compreendendo sua realidade; (2) o BT Capacitador de Funções Fisiológicas em auxilia com que a criança participe de atividades para melhoria do seu estado físico, por intermédio de brincadeiras que reforcem e envolvem seu próprio cuidado, permitindo desse modo que a criança aprenda a utilizar suas capacidades fisiológicas de acordo com sua nova condição de vida; (3) e, o BT Instrucional ou Preparatório, que prepara a criança, por meio de uma brincadeira, para os procedimentos aos quais será submetida, a fim de promover sua compreensão sobre o tratamento.

O uso do BT durante a assistência de enfermagem traz diversos benefícios como fortalecimento do vínculo entre o profissional, a criança e o acompnahante, esclarecimento de dúvidas - quando usado para demonstrar técnica ou procedimento de saúde a ser realizado na criança, dissipação de medos e receios tornando a vivência do processo de saúde-doença na criança menos obscuro e automatizado facilitando a aceitação dos procedimentos necessários ao diagnóstico e tratamento da criança. Ademais, o brincar de modo terapêutico subsidia o reconhecimento das necessidades da criança e viabiliza a construção de um cuidado humanizado e de qualidade num ambiente de acolhimento. Assim é ofertado um cuidado integral, que valoriza a comunicação na linguagem adequada ao entendimento infantil (Berté, Ogradowski,Zagonel, Tonin,Favero, \& Almeida Júnior, 2017).

O Conselho Federal de Enfermagem (COFEN) reconhece o BT como competência do enfermeiro desde 2004, e em sua Resolução $n^{\circ}$ 0546/2017 amplia essa visão quando dispõe sobre a utilização da técnica do brinquedo terapêutico como competência de toda a Equipe de Enfermagem que atua na área pediátrica. Para isso, ressalta a importância da prescrição e supervisão do Enfermeiro, de forma a contemplar as etapas do Processo de Enfermagem, inclusive o registro pelo autor da ação (Brasil, 2017). No âmbito da assistência de enfermagem pediátrica, a utilização do BT demonstra diversos benefícios não só para a criança e família, mas também para o enfermeiro, equipe e o ambiente de cuidado apresentando-se enquanto ferramenta de intervenção. Contudo, mesmo com os reconhecidos benefícios, ainda existem dificuldades na aplicação do BT pela equipe de enfermagem como parte do cuidado (Maia et al., 2019).

Essas dificuldades iniciam desde a formação acadêmica e profissional, em que a equipe de enfermagem refere a pouca abordagem do BT durante a formação técnica e/ou graduação de Enfermagem. A falta de tempo para dedicar a realização da sessão do BT, a falta de conhecimento, a insegurança em usar o BT, a falta de capacitações sobre a temática e ambiente e infraestrutura inadequados para realização da técnica são relatos comuns de profiosionais de enfermagem (Berté et al., 2017).

A partir disto, esta investigação tem por objetivo conhecer a percepção da equipe de enfermagem sobre o Brinquedo Terapêutico (BT) durante a hospitalização pediátrica, norteada pelo seguinte questionamento: qual é a percepção da equipe de enfermagem acerca do brinquedo terapêutico para na hospitalização pediátrica?

\section{Metodologia}


Estudo descritivo, com abordagem qualitativa. O cenário do estudo foi a Clínica Pediátrica de um Hospital Universitário (HU), em Maceió, Alagoas, nordeste do Brasil. A Clínica Pediátrica possui capacidade para 24 (vinte e quatro) leitos. O atendimento promovido segue os parâmetros do Sistema Único de Saúde (SUS).

Os participantes da pesquisa foram 19 profissionais de enfermagem em diferentes funções, ambos os sexos, do serviço diurno e noturno, em atividades assistenciais e gerenciais, vinculados ao HU. Foram incluídos todos os profissionais de enfermagem da Clínica Pediátrica do HU, e os critérios de exclusão foram aqueles profissionais da equipe de enfermagem que tinham menos de 12 meses de vínculo no setor, estavam de férias, licença maternidade ou recusaram-se a participar.

A coleta de dados ocorreu do período de setembro a dezembro de 2019, através de entrevistas individuais, utilizando formulário semiestruturado, constituído por perguntas destinadas ao registro de informações sobre as características gerais e profissionais, e também por perguntas norteadoras para investigação do significado do BT na assistência de enfermagem à criança hospitalizada. Para complementar as informações, foi utilizada a observação não-estruturada na obtenção de dados sobre a dinâmica do processo de cuidado da equipe na unidade Pediátrica durante todo o processo de coleta de dados.

De acordo com as orientações de Trentini, Paim e Silva (2014) as entrevistas foram gravadas e transcritas na íntegra. Para a análise dos dados seguiu-se os processos de análise de conteúdo, dividindo essa fase em duas etapas: análise (processo de apreensão) e interpretação (processo de síntese, teorização e transferência). As falas descritas foram identificadas pela ordem das entrevistas precedida pela inicial de sua categoria, a fim de não haver identificação dos mesmos. Assim, para os enfermeiros foi usada a inicial "E", para os técnicos de enfermagem foi usada a inicial "T" e para os auxiliares de enfermagem, a inicial "A" acompanhadas por um número ordinal que indica a sequência na entrevista.

Cumpriu-se com as Resoluções Éticas Brasileiras, seguindo a Resolução CNS 466/2012, que regulamenta a realização de pesquisas envolvendo seres humanos, conforme Parecer nº: 95730418.6.0000.5013.

\section{Resultados e Discussão}

A seguir foram apresentadas as características gerais e profissionais dos participantes e as 3 categorias emergidas na análise de dados da investigação do significado do BT na assistência de enfermagem à criança hospitalizada: a hospitalização pediátrica para a equipe de enfermagem, o uso do brinquedo no hospital e o brinquedo terapêutico para a equipe de enfermagem.

\subsection{Caraterísticas dos Participantes}

Dos 19 participantes, 7 eram enfermeiros, 8 técnicos de enfermagem e 4 auxiliares de enfermagem. Dentre eles, 17 eram do sexo feminino e 2 do sexo masculino, com idades entre 29 e 60 anos. $O$ tempo de formação profissional variou entre 8 anos e 37 anos. E o tempo de atuação na hospitalização pediátrica variou entre 12 anos e 35 meses. Apenas 1 deles possui mestrado, e nenhum deles possui especialização em enfermagem pediátrica ou áreas afins.

\subsection{A hospitalização pediátrica para a equipe de enfermagem}

Os profissionais de enfermagem participantes mostraram-se sensíveis a aspectos da hospitalização na infância, sempre preocupados com a interferência na realidade vivida anteriormente pela criança e demonstrando preocupação com as consequências da rotina hospitalar para as mesmas, como expresso pelas falas:

“Porque elas vêm para um ambiente tão fora da realidade delas, da casa delas, da escola[...]” (T6) 
"A gente percebe que para a criança que está aqui é muito frio o hospital. O ambiente é muito inóspito para eles. Então assim, é muita agressão, a gente sente invadir muito eles, entendeu?" (E8)

"Porque ficar preso aqui o tempo todo, a gente fica aqui algumas horas e vai embora, elas não, tem gente que passa 2 meses, 3 meses aqui[...]" (A5)

Os profissionais tem uma percepção compreensiva do processo de ruptura que a criança vive dentro de um novo ambiente impregnado de incertezas. A hospitalização pediátrica apresenta diversos processos que influenciam negativamente a criança como um ambiente desconhecido, longe do convívio familiar, dos amigos, brincadeiras e escola (Caleffi, Rocha, Anders, Souza, Burciaga \& Serapião, 2016).

A assistência à criança hospitalizada é uma tarefa difícil, que muitas vezes traz sentimentos de tristeza, frustração e insuficiência para os profissionais envolvidos nesse processo. O convívio contínuo com tais pacientes atrelado a possibilidade de morte iminente de alguns desses provoca esse sentimento de angústia nos profissionais (Santos, Rodrigues, \& de Deus Martins, 2018).

Os longos períodos de internação e o afastamento das atividades escolares também foram assuntos que geraram angústia nos profissionais, uma vez que não havia intervenções pedagógicas na referida instituição.

"As crianças ficam muito afastadas da escola, elas perdem muito com isso. Tem criança aqui que já perdeu o ano, que perdeu o interesse de estudar, porque vai perdendo o ano, vai uma semana, volta, fica um mês, dois meses, até três meses fora da escola." (T2)

"Acho que o hospital deveria dar uma continuação da escola, porque às vezes eles passam 2 meses, 4 meses, aqui internados, aí já fica fora da escola, mas o hospital deveria ter uma equipe para dar continuidade, para que a criança não perdesse aquele ânimo.” (T3)

O comportamento de estudar no ambiente hospitalar, além de tornar-se uma prática de distração, é também um importante regulador do sistema emocional e cognitivo, contribuindo para o enfrentamento das adversidades durante a hospitalização. As ações pedagógicas quando atreladas às atividades lúdicas são ainda mais eficientes sendo um importante elo da infância com o contexto hospitalar, ao passo que resgatam as atividades típicas dessa fase da vida, ao qual elas tiveram que afastar-se, mesmo que temporariamente, em razão da hospitalização (Menzani, Regueiro \& de Cassia Leiva, 2017).

Nesse estudo, os profissionais também referiram a importância das atividades lúdicas no contexto hospitalar, relatando o interesse das crianças e o alívio da tensão tanto para as mesmas, como para os profissionais e acompanhantes.

"Tem as pessoas que fazem o trabalho, das instituições de ensino, ai vem nos finais de semana ou outros dias festivos para trabalhar com elas a questão do brinquedo, da ludicidade, isso aí envolve muito elas, e muitas delas esquecem. [...] Elas falam muito da brinquedoteca, do dia que abre, da hora que vai abrir, elas ficam naquela expectativa, naquela ansiedade de abrir a brinquedoteca. [...]" (T10)

"Eu entendo que o brinquedo traz para a criança a ideia de que ela ainda é uma criança e que ela pode fazer tudo que ela tem necessidade, mesmo estando no hospital. E a brinquedoteca, o que eu vi da brinquedoteca, é que ela fez renascer isso nas crianças, porque é tudo muito mecânico [...] o brinquedo não é mecânico, o brinquedo ele traz um sentimento junto com ele, ele traz uma alegria [...]”" (T11) 
O brincar e a brincadeira no cenário hospitalar são recursos vistos pelas crianças como capazes de minimizar a ansiedade e o medo desse ambiente, referindo à importância de profissionais que brinquem e sejam engraçados, incluindo atividades lúdicas durante sua hospitalização (Hostert, Motta, \& Enumo, 2015). Assim o brincar e o brinquedo ganham um aspecto importante no alívio dessas angústias, tanto das crianças, quanto dos profissionais e dos familiares. A brincadeira além de distrair, proporciona para a criança uma outra visão do ambiente hospitalar, fornecendo um cuidado diferenciado e podendo melhorar a sua compreensão sobre esse processo (Santos et al., 2018).

\subsection{O uso do brinquedo no hospital}

Quando se indagou a respeito das vivências com o uso do brinquedo no hospital doze profissionais expressaram ter tido alguma experiência anterior, porém sete deles não recordavam de nenhuma. As vivências não foram referidas claramente com o uso do BT, pois os profissionais se reportam ao brinquedo apenas como uso recreativo.

"A gente vivencia muito as crianças que geralmente chegam quando vem pra internar, que muitas vezes elas vêm com um brinquedo delas, que elas têm um apego e que trazem pra cá" (E1)

"Eles tragam para o hospital o lar, o habitat deles natural. Então eles ficam mais ambientalizados, vendo a sua casa no hospital, e transforma esse período de trauma em felicidade para eles." (T7)

O uso do brinquedo durante a internação contribui positivamente na melhora do estado emocional, na alegria, disposição, e comunicação da criança (de Melo Silva, Salustino dos Santos, Marinho da Silva, Ferreira, Gouveia, Rodrigues, \& Alcoforado dos Santos, 2018). Este aspecto foi observado e relatado por 18 dos profissionais, assim também partilham os benefícios do brinquedo no ambiente hospitalar. Nas vivências referidas pelos participantes observam-se que outros elementos lúdicos foram muito citados, muitas vezes até com sentido de sinônimos do brinquedo. Assim, observa-se que os profissionais usam e citam recursos lúdicos diversos, porém ainda há pouca utilização do brinquedo no cuidado de enfermagem e do BT com suas finalidades específicas.

"Eles têm um momento aqui, que é dos doutores da alegria, que vem aqui no sábado fazer aquela festa e tal..." (E8)

"É porque o brinquedo é muito importante, inclusive tem o grupo sorriso de plantão [...]Tem a brinquedoteca né $[\ldots] "(T 14)$

Doze profissionais referiram que pouco utilizam ou nunca utilizaram o brinquedo durante sua atuação profissional. Não obstante, os estudiosos da Silva, Schmidt, Grigol, \& Schultz (2020), que realizaram uma investigação qualitativa num hospital da região norte de Santa Catarina, concluíram a partir do relato de 10 enfermeiros do setor pediátrico que as razões para a não utilização do BT foram falta de tempo, preocupação com as demandas da rotina, a quantidade de funcionários e múltiplas atribuições.

"Não. Porque geralmente quando eu era da pediatria na outra instituição, a gente nunca desenvolvia essa terapia com as crianças porque tinha o pessoal que fazia essa parte, que é o pessoal da T.O. [Terapia Ocupacional] , a gente ficava mais com essa parte da assistência de enfermagem mesmo." (T6) 
Outro fato observado refere-se às experiências citadas do uso do brinquedo, que foram muitas vezes relacionadas ao momento do procedimento. Fato também encontrado por Santos et al. (2018), uma vez que o brinquedo ajuda no entendimento e compreensão do procedimento pela criança e facilita a sua realização.

"O primeiro contato que eu tive, foi durante uma punção, eu não lembro quem foi, quem foi o profissional que veio ali com um brinquedo, no momento ali que a gente estava focado na técnica e que fez uma diferença imensa para a criança, aquele brinquedinho..." (E19)

"O próprio brinquedo da criança, para fazer a medicação e tal, ele gosta do brinquedo ali ou de visualizar alguma imagem relacionada ao brinquedo, até ele se aquieta e recebe "de boa" a medicação." (T7)

O uso do brinquedo, em alguns momentos, não foi visto como parte da assistência de enfermagem pelos profissionais, e quase sempre esteve vinculado à distração e ao bem estar da criança, sendo pouco comentado quanto ao seu benefício para a melhora da compreensão dos procedimentos pelas crianças.

O uso do brinquedo durante a realização de procedimentos favorece a compreensão e aceitação de sua condição clínica e necessidade de cuidados específicos durante a assistência de enfermagem (dos Santos et al., 2020). A capacidade de compreensão da criança é frequentemente subestimada pelos profissionais e familiares, tornando o meio hospitalar ainda mais ameaçador, ao passo que ela não vai sendo comunicada adequadamente sobre os cuidados que lhes serão prestados. O BT surge como uma importante estratégia para essa comunicação e precisa não só ter sua importância reconhecida como também ter a técnica conhecida, instrumentalizada e implantada pela equipe de enfermagem (de Melo Silva et al., 2018).

\subsection{O brinquedo terapêutico para a equipe de enfermagem}

O BT é uma brincadeira estruturada que surge com o propósito de reduzir esses efeitos adversos da hospitalização pediátrica (da Silva et al., 2020). Embora exista uma literatura ampla em relação ao uso do BT pelos profissionais de enfermagem, o seu uso na prática clínica ainda é modesto; e muitos profissionais ainda pouco conhecem a técnica do BT (Menzani et al., 2017).

Todos os profissionais participantes desconheciam a técnica do BT. Ao serem questionados sobre o conceito dessa, apenas um dos profissionais se aproximou da finalidade do BT , definindo-o como instrucional.

"Um brinquedo que fizesse parte do tratamento, tipo: tem gente que traz aquelas coisas de estetoscópio e não sei o que lá, que o doutor usa [...] Essa menininha, por exemplo, está com medo da sonda, e eu fui explicar pra ela e senti falta de uma coisa palpável para poder explicar a ela. Se eu fosse fazer um brinquedo terapêtico, e se for isso que eu estou pensando, eu faria um boneco com uma sonda, e que ela visse a sonda e que pudesse pegar e ver: ah, ela vai pra ali... que não assustasse” (E18)

Os demais entrevistados se aproximaram pouco dos conceitos e finalidades de algum dos 3 tipos de BT. Alguns profissionais relacionaram com o estímulo ao desenvolvimento da criança. E grande parte deles trouxe a finalidade do alívio da dor e do sofrimento durante a hospitalização.

"Entendo que é algo, que naquele momento que a criança está em tratamento, que está passando por alguma hospitalização, que aquilo vá aliviar o sofrimento dele, a dor, a distância de casa, que vá trazer ele mais próximo da realidade dele." (E1) 
O BT é também uma importante ferramenta na redução da dor em procedimentos, como punção venosa ou troca de curativos, sendo uma estratégia importante para o cuidado de enfermagem na hospitalização pediátrica, facilitando a compreensão e aceitação de procedimentos e melhorando o relacionamento entre profissionais e criança, ao passo que reduz a dor (de Almeida Gomes, Silva, dos Santos, \& de Castro Palermo, 2019). Alguns relatos também trazem como objetivo principal da técnica a distração e o conforto, com a diminuição do sofrimento durante os procedimentos.

"Eu geralmente quando vou fazer algum procedimento, eu tento chamar a atenção da criança, e elas sempre me conhecem por eu ter uma coisa que envolve elas." (T10)

"É um brinquedo que você vai usar ali num momento pra distrair, vê se diminui essa questão da dor..,distrair a criança, acho que é esse o foco." (E9)

O que coincide com a literatura existente, em que essa técnica realizada previamente aos procedimentos é muito eficaz para diminuir as manifestações emocionais negativas e ansiedade das crianças durante os procedimentos (Santos, Almeida, \& Ribeiro, 2020).

O brinquedo também aparece como possível mediador para uma conversa ou interação entre o profissional e a criança, conforme as falas de alguns dos entrevistados.

"Utilizaria no momento de alguma visita que eu fosse passar, ou ter que conversar alguma coisa com aquela criança maiorzinha. Também usaria o brinquedo como uma fonte para ensinar a ela, para que ela assimilasse mais.” (E1)

“Uns bonequinhos de mãos dadas, tudo juntinho, pode representar uma família... quantos irmãos você tem? Ai conte aí... quem é esse? Quem é aquele? Quem é o mais velho? Quem é o mais novo? Quem é o papai? Coloque um bigode! Quem é a mamãe?... Isso para a criança passa a ser uma terapia, ele vai identificar a mãe, o pai, o irmão mais velhos, o mais novo, o cachorrinho, o gato” (T13)

É possível observar que mesmo sem conhecer a técnica do BT, muitas falas convergem para os princípios do BT, como nas falas acima. A primeira traz um pouco a finalidade do BT instrucional ou preparatório e do BT capacitador de funções fisiológicas. A segunda fala simula uma sessão de BT dramático. As crianças através da sessão de BT dramático podem falar dos personagens referindo-se a situações semelhantes às vivenciadas por elas (Santos et al., 2020)

Ao passo que a equipe de Enfermagem reconhece o brinquedo como uma necessidade da criança, propicia meios para a realização da técnica do BT de forma sistemática, no cuidado prestado à criança hospitalizada, favorecendo a melhor comunicação e diminuição da tensão e ansiedade diante dos procedimentos (dos Santos, de Souza, Farias \& de Andrade Aoyama, 2020).

Reconhecendo essa necessidade, o COFEN entende o BT como competência de toda a equipe de enfermagem, devendo essa técnica contemplar as etapas do Processo de Enfermagem desde a prescrição do enfermeiro até o registro em prontuário pelo autor das ações. Mas todos os profissionais entrevistados desconheciam as resoluções do COFEN sobre o BT. E alguns deles referiram a utilização do brinquedo como algo dissociado da assistência de enfermagem e atribuindo a outros profissionais essa competência (Brasil, 2017). 
"Aí o termo do brincar com a criança já fica mais complicado para a gente porque não dá tempo. Aí tem que ficar mais com a parte da pedagogia, da terapia... a enfermagem vai fazer a parte dela, que é os cuidados, né.” (T3)

"Porque fica bem mais restrito para a área de T.O. e psicologia mesmo, não entra na parte de enfermagem não." (A5)

"Não, porque eu sou de atuar mais no lado profissional." (A15)

Os profissionais referiram que nenhum deles viu prescrição para o uso do BT durante sua atuação profissional, apenas indicações informais. E apenas dois profissionais referiram algum tipo de registro do uso do brinquedo no hospital. E em algumas falas ficou destacado que o uso do brinquedo não era visto como um cuidado de enfermagem.

"Escrito não. Mas aqui a brinquedoteca é sempre indicada, para que as crianças façam a terapia dentro da brinquedoteca, para que ela frequente a brinquedoteca." (T10)

"A gente às vezes nas nossas evoluções... a gente dia de sábado recebe o sorriso de plantão, aí assim, a gente bota, porque às vezes tem aquela criança que estava mais tristinha, aí na evolução a gente coloca: criança hoje animou-se com a presença do palhaço." (E1)

"Não. Geralmente a gente não anota essas coisas." (T10)

A ausência de registro das intervenções de enfermagem, a equipe mostra desconhecer esse cuidado, dificultando ver o paciente em sua singularidade e prejudicando a realização de pesquisas sobre a assistência de enfermagem. Em outras palavras, os cuidados da equipe de enfermagem, de um modo geral, ficam imperceptíveis diante do ambiente hospitalar, uma vez que dificulta a identificação do processo de enfermagem no processo de trabalho da área da saúde (Ferreira, Chiavone, Bezerril, Alves, Salvador \& Santos, 2020).

Muitas vezes a não utilização do brinquedo é justificada por algumas dificuldades encontradas, essas se iniciam desde o pouco contato dos profissionais com o BT durante seu período de formação acadêmica.

"Na época que era enfermeiranda, a gente não passava aqui pela pediatria, então a gente teve muita pouca vivência com a questão do brinquedo usado de forma terapêutica, né. E tinham muitos menos pacientes do que tem hoje, então essa parte aí brinquedo só tenho visto aqui na pediatria quando eu comecei a trabalhar [...]” (E16)

Esta fala evidencia a carência em refletir e criticar a instrumentalização do BT no campo prático, como um procedimento de cuidado à criança, construída oportunamente desde a formação acadêmica, com docentes que estimulem e facilitem este conhecimento, proporcionando ao acadêmico essa oportunidade de vivência (Falke, Milbrath \& Freitag, 2018). Permitir que este acadêmico se aproprie do recurso como prática de enfermagem deve ser acompanhado da perspectiva ampla de sua aplicação, como por exemplo em que momento implementar este cuidado e como implementar, o quanto de recursos humanos e materiais serão investidos, de que modo irá afetar outros cuidados também importantes.

"A gente tem um horário muito corrido, a parte da medicação a ser administrada, tem que dar mais atenção a esse lado, aí o termo do brincar com a criança já fica mais complicado para a gente porque não dá tempo [...] a enfermagem vai fazer a parte dela, que é os cuidados, né." (T3) 
"Tem dias que a gente tem muitos procedimentos para fazer, então a gente tem que ter um pouquinho mais de cautela e de agilidade também, para a gente dar continuidade à assistência aos outros pacientes também. Eu acho que dificuldade pode estar aí, muitas vezes, nessa sobrecarga [...]” (E9)

Identificou-se um discurso convergente para a "falta de tempo" da equipe de enfermagem para a aplicação da técnica do BT, sendo esse o fator principal apontado para a não realização. Este fator também foi referido por profissionais de enfermagem em outra investigação associada a quantidade reduzida de profissionais diante das demandas do setor (Ferreira et al., 2020; Silva et al, 2020). A falta de tempo é a mais frequente justificativa apresentada pelos profissionais de enfermagem como desafio para a implementação do recurso do BT, em face da grande demanda de cuidados biológicos que a criança hospitalizada requer. Na investigação de Santos et al. (2018) e de Silva et al. (2020) é possível perceber a complexa atenção que o cuidado de enfermagem alcança, bem como a lacuna que se abre com as necessidades psicossocias e de neurodesenvolvimento que a criança possui.

Isto só realça e pouca compreensão que se tem a respeito do BT como recurso terapêutico, pois a sua implementação pode ser realizada pelos profissionais de enfermagem sem causar desgaste ou atrasos nas suas demais atividades de cuidado. Uma vez que só mudará a abordagem e não demandará tempo adicional para tanto. Além disso, pode possibilitar uma melhor recuperação, ao passo que melhora a assistência, tornando-a mais integral e humanizada, e o processo de hospitalização menos traumático (Falke, Milbrath \& Freitag, 2018)

Algumas dificuldades que sobrepõem a falta de tempo foram citadas, como os profissionais que trabalham apenas no turno noturno, assim como, os pacientes com quadros mais graves que demandam uma maior atenção da equipe. Além disso, emergiu das entrevistas a gravidade dos pacientes e a dependência de cuidados, a falta de envolvimento de toda a equipe, a necessidade de capacitações e a preocupação com o brinquedo como possível veículo de transmissão de infecções e a falta de preparo da equipe de enfermagem para a utilização deste recurso.

No entanto, também foram apontados alguns fatores que podem facilitar a aplicação da técnica do BT, como a brinquedoteca no hospital, uma sala de procedimentos com ambiência adaptada à abordagem humanizada à criança e a atuação da equipe multiprofissional. Outra dificuldade que ficou implícita em algumas falas, foi a do brinquedo como veículo de transmissão de infecções cruzadas, para aqueles brinquedos de uso compartilhado.

"A questão dos brinquedos nas enfermarias, a gente tenta ao máximo não deixar muito pela questão da infecção, aí a gente tem esse cuidado." (E1)

"Eu acho que tem que ter padrões para algumas determinadas situações, tipo: brinquedo que seja lavável, o brinquedo não pode passar de uma criança pra outra sem ter um cuidado [...]” (E18)

A veiculação de microorganismos patogênicos por meio dos brinquedos é uma realidade nos casos em que não são adotadas rotinas de higienização dos mesmos. É de grande importância que os profissionais que os utilizam estejam atentos para a sua limpeza e desinfecção, e que esse não seja o motivo de privar a criança de brincar, uma vez que esse é um direito assegurado pelo Estatuto da Criança e do Adolescente (Boretti, Corrêa, Santos, Leão \& Silva, 2014).

É importante ressaltar que o uso do BT se dá de maneira estruturada. Ou seja, ele é realizado com uma finalidade, em um tempo determinado e de maneira individualizada, fazendo com que exista um preparo antes e ações após o procedimento, com isso deve-se constituir como parte do preparo a higienização dos materiais, assim como a escolha de materiais que permitam a mesma (dos Santos, de Souza, Farias \& de Andrade Aoyama, 2020). 


\section{Conclusão}

$\mathrm{Na}$ perspectiva de diminuição do sofrimento referente a hospitalização, os profissionais reconhecem o uso do brinquedo no ambiente hospitalar como benéfico, para as crianças, familiares e para os próprios profissionais da equipe de saúde. A técnica do BT ainda é pouco compreendida pela equipe de enfermagem, sendo a utilização do brinquedo mais relacionada aos momentos de procedimentos, para aliviar o medo e a ansiedade, também para a distração e redução da dor da criança nesses momentos, de maneira assistemática. Essas impressões dos profissionais aproximam-se dos tipos e das finalidades do BT, mas esses ainda não a entendem como uma técnica, e esses achados sinalizam para a importância e necessidade de capacitações para a efetiva implementação desse cuidado no contexto do cuidado pediátrico.

Os participantes do estudo ainda desconhecem as legislações do conselho de enfermagem a respeito do BT, e geralmente, dissociam o uso do brinquedo do cuidado de enfermagem. Isso evidencia a necessidade das instituições de saúde implantarem a prática do uso do brinquedo nas unidades pediátricas. Para a mudança dessa realidade, alguns esforços são necessários, como, a realização de sensibilizações e capacitações iniciais e periódicas para os profissionais de enfermagem em relação à humanização, uso de tecnologia leves de cuidado, ao uso do brinquedo, a técnica do BT e as legislações sobre o tema, promovendo a reflexão sobre sua práxis e os benefícios para equipe, crianças, familiares e comunidade.

\section{Referências}

Almeida, F. (2019) O uso do brinquedo terapêutico e a humanização da assistência à criança cirúrgica. Revista SOBECC, 24(3): 117-118. https://www.revista.sobecc.org.br/sobecc/article/view/554

Barroso, M. C. C. S., Machado, M. E. D., Cursino, E. G., Silva, L. R., Depianti, J. R. B., \& Silva, L. F. (2019) O brinquedo terapêutico na graduação de enfermagem: da teoria à prática. Revista Fun Care Online, 11(4): 1043-1047. http://www.seer.unirio.br/index.php/cuidadofundamental/article/view/6901.

Berté, C., Ogradowski, K. R. P., Zagonel, I. P. S., Tonin, L., Favero, L., \& Almeida Junior, R. L. (2017) Brinquedo terapêutico no contexto da emergência pediátrica. Revista baiana enfermagem, 31(3): e20378. https://portalseer.ufba.br/index.php/enfermagem/article/view/20378/15101.

Boretti, V. S., Corrêa, R. N., Santos, S. S. F. dos, Leão, M. V. P., \& Silva, C. R. G. (2014). Perfil de sensibilidade de Staphylococcus spp. e Streptococcus spp. isolados de brinquedos de brinquedoteca de um hospital de ensino. Revista Paulista de Pediatria, 32(3), 151-156. https://dx.doi.org/10.1590/01030582201432301

Brasil. Conselho Federal de Enfermagem. Resolução COFEN nº 0546 (2017) Utilização de técnica de brinquedo terapêutico pela En fermagem. In: Diário Oficial da União, (93):136, Brasília, 2017 http://www.cofen.gov.br/resolucao-cofen-no-05462017_52036.html.

Brasil. Lei 13.257/2016. In: Diário Oficial da União, Brasília, (2016). http://www.planalto.gov.br/ccivil_03/_ato2015-2018/2016/lei/113257.htm

Caleffi, C. C. F., Rocha, P. K., Anders, J. C., Souza, A. I. J. de, Burciaga, V. B., \& Serapião, L. da S. (2016). Contribuição do brinquedo terapêutico estruturado em um modelo de cuidado de enfermagem para crianças hospitalizadas. Revista Gaúcha de Enfermagem, 37(2), e58131.https://doi.org/10.1590/1983-1447.2016.02.58131

Cavalcante, A. M. R. Z., Lopes, C. T., Swanson, E., Moorhead, S. A., Bachion, M. M., \& Barros, A. L. B. L. de. (2020). Validação de definições para indicadores do resultado NOC: Autocontrole da doença cardíaca. Acta Paulista de Enfermagem, 33, e-APE20180265. 23, 2020.https://dx.doi.org/10.37689/acta-ape/2020ao0265

Depianti, J. R. B., Melo, L. L., \& Ribeiro, C. A. (2018). Playing to continue being a child and freeing itself from the confinement of the hospitalization under precaution. Escola Anna Nery, 22(2), e20170313. https://doi.org/10.1590/2177-9465-ean-2017-0313

Dos Santos, G. M., de Souza, L. P., Farias, F. C., \& de Andrade Aoyama, E. (2020). A influência do brinquedo terapêutico no cuidado à criança em ambiente hospitalar. Revista Brasileira Interdisciplinar de Saúde ReBIS 2(2). 40-5. https://revistarebis.rebis.com.br/index.php/rebis/article/view/86/79

Falke, A. C., Milbrath, V., \& Freitag, V. (2018) Estratégias utilizadas pelos profissionais da enfermagem na abordagem à criança hospitalizada. Rev Contexto \& Saúde, 18(34):9-4. https://www.revistas.unijui.edu.br/index.php/contextoesaude/article/view/7194.

Ferreira, L. B., Oliveira, J. S. A., Gonçalves, R. G., Elias, T. M. N., Medeiros, S. M., Mororó, D. D. S. (2019) Cuidar de enfermagem às famílias de crianças e adolescentes hospitalizados. Revista de Enferm UFPE online, 13(1):23-31. https://periodicos.ufpe.br/revistas/revistaenfermagem/article/d ownload/237672/31107

Ferreira, L. de L., et al. (2020). Análise dos registros de técnicos de enfermagem e enfermeiros em prontuários. Revista Brasileira de Enfermagem, 73(2), e20180542..https://doi.org/10.1590/0034-7167-2018-0542 
Research, Society and Development, v. 10, n. 5, e51510515216, 2021

(CC BY 4.0) | ISSN 2525-3409 | DOI: http://dx.doi.org/10.33448/rsd-v10i6.15216

Hostert, P. C. D. C. P., Motta, A. B., \& Enumo, S. R. F. (2015) Coping da hospitalização em crianças com câncer: a importância da classe hospitalar. Estudos de Psicologia.32(4), 627-639. http://www.scielo.br/scielo.php?script=sci_arttext\&pid=S0103-166X2015000400627\&lng=en\&nrm=iso.

Maia, Edmara Bazoni Soares, Ohara, Conceição Vieira da Silva, \& Ribeiro, Circéa Amália. (2019). Teaching of therapeutic play at the undergraduate level in nursing: didactic actions and strategies used by professors. Texto \& Contexto - Enfermagem, 28, e20170364.. https://doi.org/10.1590/1980-265x-tce-20170364

Menzani, R. M., Regueiro, E. M. G., \& de Cassia Leiva, J. (2017). Ser criança na classe hospitalar: a dimensão psicológica na interface educação e saúde. Revista Brasileira Multidisciplinar, 20(1), 106-120. http://www.revistarebram.com/index.php/revistauniara/article/view/476.

Rockembach, J., Espinosa, T., Cecagno, D., Thumé, E. \& Soares, D.C (2017) Inserção do lúdico como facilitador da hospitalização na infância: percepção dos pais. Journal Nurse Health, 7(2):117-26. https://periodicos.ufpel.edu.br/ojs2/index.php/enfermagem/article/view/7646/7882

Santos, D. V. S., Rodrigues, F. M. S., \& de Deus Martins, M. (2018). Percepções da equipe de enfermagem quanto ao cuidado pre stado à criança em cuidados paliativos e sua família/Staff perceptions related to the nursing care provided to the child and family during palliative care. Arquivos Médicos dos Hospitais e da Faculdade de Ciências Médicas da Santa Casa de São Paulo, 63(3), 198-202. http://arquivosmedicos.fcmsantacasasp.ed u.br/index.php/AMSCSP/article/view/482

Santos, V. L. A. D., Almeida, F. D. A., Ceribelli, C., \& Ribeiro, C. A. (2020). Compreendendo a sessão de brinquedo terapêutico dramático: contribuição para a enfermagem pediátrica. Revista Brasileira de Enfermagem, 73(4). https://doi.org/10.1590/0034-7167-2018-0812

Silva, C da., Schmidt, F. M., Grigol, A. M., \& Schultz, L. F. (2020). O enfermeiro e a criança: a prática do brincar e do brinquedo terapêutico durante a hospitalização. Semina: Ciências Biológicas e da Saúde, 41(1), 95-106. http://www.uel.br/revistas/uel/index.php/seminabio/article/view/36359

Silva, S. R.M, Santos, M. C. S, Marinho da Silva, A., Ferreira, F. Â., Gouveia, M. T., Ferreira Guedes Rodrigues, W., \& Alcoforado dos Santos, R. E. (2018). Perception of the hospitalized child's companion in relation to therapeutic toys. $J$ Nurs UFPE online, 12(10): 2703-9 https://periodicos.ufpe.br/revistas/revistaenfermagem/article/view/236309

Trentini, M., Paim, L., \& Silva, D. M. G. V. (2014). Pesquisa convergente assistencial: delineamento provocador de mudanças nas práticas de saúde. 175, 175p. https://www.scielo.br/pdf/tce/v26n4/0104-0707-tce-26-04-e1450017.pdf 